\title{
Butterflies (Lepidoptera) highlight the ecological value of shrubland and grassland mosaics in Cypriot garrigue ecosystems
}

\author{
ÖZGE ÖZDEN ${ }^{1,2}$ and DAVID J. HODGSON² \\ ${ }^{1}$ Faculty of Agricultural Sciences and Technologies, European University of Lefke, Mersin 10, North Cyprus; \\ e-mail: ozgeozden77@yahoo.com \\ ${ }^{2}$ Centre for Ecology and Conservation, University of Exeter, Cornwall Campus, Tremough, Penryn, Cornwall TR10 9EZ, UK; \\ e-mail: d.j.hodgson@exeter.ac.uk
}

Key words. Butterflies, Lepidoptera, garrigue, habitat, conservation, Cyprus

\begin{abstract}
We used butterfly assemblages to evaluate the ecological value of habitat mosaics within garrigue ecosystems in Cyprus. To understand the importance of the local plant communities for Cypriot butterflies, five plots in each of two habitat types (grassdominated or shrub-dominated) were surveyed weekly for a period of five months in order to assess the abundance, species richness and diversity of butterflies. A total of 810 butterflies of 16 species were recorded. Indices of butterfly diversity, calculated across the whole season, were similar between grassland and shrubland dominated mosaics. However, species richness of all butterflies was consistently higher in grassland dominated mosaics throughout the whole season. The peak abundance of all butterfly species occurred during mid-season (late April - early May), with similar numbers observed in both habitat types. However, a greater abundance was observed during early and late season in grassland patches. The abundance of endemic species (Maniola cypricola, Hipparchia cypriensis, Glaucopsyche paphos) peaked earlier in the season in shrubland patches, but was higher in grassland patches in late season. This difference in seasonal timing of endemic abundance was dominated by the seasonal dynamics of $M$. cypricola. These results suggest that, while garrigue is characterised by its shrub flora, management to maintain a mosaic of grassland and shrubland could act to maximise the abundance and richness of indicator species groups of conservation importance.
\end{abstract}

\section{INTRODUCTION}

The Mediterranean region has been recognized as one of the 18 world biodiversity "hotspots", holding the world's second highest percentage of endemic species (Myers, 1990; Blondel \& Aronson, 2004). The area is surrounded by mountain landscapes, covered by scrub and woodlands, and is home to approximately 25,000 species of flowering plants, of which 1,300 are endemic. Conservation strategies within the Mediterranean Basin play a crucial role, due to the fact that the Mediterranean region is the world's leading tourist destination (Ornat \& Correas, 2003). Mass tourism and its resultant commercial developments have led to seriously degraded landscapes and a dramatic loss of natural habitats (Myers et al., 2000; Ornat \& Correas, 2003).

Island faunas and floras have always been of great concern for conservationists (Dapporto \& Dennis, 2008; Dennis et al., 2008) as they often possess high levels of diversity and endemism. Cyprus is the third largest island in the Mediterranean Sea, situated at the north-eastern end of the Eastern Mediterranean Basin, and is one of the European hotspots of biodiversity and endemism (Medail \& Quezel, 1999; Myers et al., 2000; Nadin, 2008). It covers an area of $9251 \mathrm{~km}^{2}$ and is divisible into four geomorphologic zones; the Kyrenia range, the Troodos mountains, the Mesoria plain (positioned between the Kyrenia range and Troodos mountains), and the Mamonia complex in south west Cyprus (Phillips \& Bracewell, 2001; Tsintides et al., 2002; USAID, 2006). The Cypriot fauna includes 11 species of land mammals, 27 species of amphibians and reptiles, 370 species of birds, and a great variety of invertebrates (USAID, 2006). Typical of many islands, Cyprus has a large number of endemic plant species (Tsintides et al., 2002). To date in Cyprus, 52 species of butterflies have been recorded (John et al., 2006). This includes three endemic species (Maniola cypricola, Hipparchia cypriensis, Glaucopsyche paphos) and two endemic subspecies (Hipparchia syriaca cypriaca and Chazara briseis larnacana) (Olivier, 1993; Makris, 2003; John et al., 2006). Two of the endemic species M. cypricola and G. paphos are of European Conservation Concern (van Swaay \& Warren, 1999).

The vegetation in Cyprus is diverse, constituting woody plants, pine forests, sclerophyllous evergreens, high and low maquis, phrygana and, of most relevance to this research, garrigue (USAID, 2006; Tsintides et al., 2002). Garrigue is composed of evergreen sclerophyllous or lauriphyllous shrub vegetation, with an open canopy structure and some bare ground, usually with many winter annuals and vernal geophytes. Eastern garrigues are shrub-like formations including Pistacia lentiscus, Myrtus communis, Calicotome villosa and Sarcopterium spinosum (Davies et al., 2004). On the northern coast of Cyprus, garrigue ecosystems vary from shrub-dominated habitat patches to grassland-dominated patches. The importance of this patchy mosaic of habitat types within the garrigue, to indicator species of biodiversity, has gained very little research attention. 
It is widely understood that grasslands and shrublands are among the biologically richest ecosystems in Europe, in particular those of the Mediterranean Basin (Stefanescu et al., 2005; Zamora et al., 2007). A study on priority sites for conservation of European butterflies showed that threatened butterfly species are present mainly in alpine/subalpine grassland, dry grassland and humid grassland areas (van Swaay \& Warren, 2006). Other research indicates that Lycaenids are known to fly preferably in rather open habitats, such as flowery and grassy meadows (Grill et al., 2005). These grassland habitats are degraded by development pressures and changes in mountain grassland management regimes (Grill et al., 2002). Grassland habitats in Cyprus provide important host plant communities for larvae of two of the endemic butterfly species (M. cypricola and H. cypriensis) (John \& Parker, 2002; Makris, 2003).

Here we use a case study of butterfly abundance and behaviour in garrigue habitats, in order to clarify the importance of grassland-shrubland mosaics for endemic butterfly species. Butterflies are popular indicator species for ecologists and conservationists, because they are charismatic, and relatively easy to identify and sample (Ulrich \& Buszko, 2003). Butterflies are commonly used as important ecological indicators for biodiversity measures in various ecosystems (Beccaloni \& Gaston, 1995; Lewis et al., 1998; Dover et al., 2000; Grill et al., 2005; Özden et al., 2008). Despite this international research effort on butterflies, there is still a paucity of research on the ecology of endemic butterfly species in Cyprus.

We compared the diversity, species richness, and seasonal dynamics of butterfly abundance/activity, between grassland and shrubland patches within the Cypriot garrigue ecosystem. Also, we recorded the behaviour of endemic butterflies and their preferred plant species, ie. on which plants do they prefer to rest or feed? Our research area constitutes one of the most important areas for wildlife on the Cyprus north-west coastline, which has Special Protected Area status and is where typical Mediterranean ecosystems, including grassland-shrubland mosaics, occur. Butterfly assemblages were used to evaluate the conservation value of the grassland patches within the garrigue ecosystem in Cyprus with the secondary aim of extending knowledge on the ecology of endemic species. We addressed the following questions: (1) Where are butterflies more abundant, in grassland dominated or in shrubland dominated habitats? (2) Do the endemic species prefer certain habitat types? (3) On which plant species do endemics prefer to rest or feed?

\section{MATERIAL AND METHODS}

\section{Study area}

This study was carried out in the north-west region of Cyprus; at the western end of the Kyrenia range (close to Kayalar village), where typical Mediterranean ecosystems are still subject to agricultural activities (sheep and goat grazing) (Fig. 1). The area has recently been designated as a potential Natura 2000 site, as it has a very high ecological value, is covered by garrigue and maquis ecosystems, and is currently declared as a Special Protected Area by the local government. The vegetation

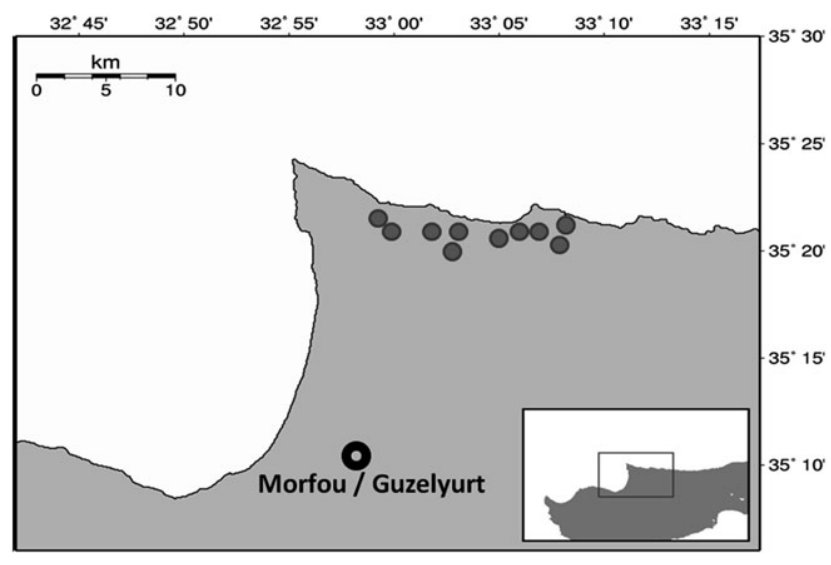

Fig. 1. Map showing the research area in the northern part of Cyprus. Gray circles signify the selected plots.

in the area is mainly dominated by Pinus brutia, Juniperus phoenica, Olea europaea, Cerotonia siliqua, Pistacia lentiscus, Thymus capitatus, Sarcopterium spinosum, Achillea cretica, Cistus spp., Valeriana italica and Genista sphacelata. During spring, there are many wild flowers in the area including Anemone coronaria, several orchid species (including the endemic orchid Ophrys kotschyi), Cyclamen graecum, Trifolium spp., Vicia peregrina. The Cypriot climate is typically Mediterranean, with hot, dry summers and mild, rainy winters.

\section{Field methods}

During this study ten different plots were established in the area, with each plot surveyed weekly between March and July, 2007. The plots were chosen with a minimum distance of $20 \mathrm{~m}$ from each other. In each plot we marked a central point, and observed the butterflies within $10 \mathrm{~m}$ radius from this centre for a total of $15 \mathrm{~min}$, between 10:00 - 14:00 in order to identify their resting locations or nectaring resources within each plot. We identified the main plant species occurring in each plot and categorised plots as grassland or shrubland (Table 1). Grassland dominated habitats consisted of $>60 \%$ grass cover and $<40 \%$ shrub cover. Shrubland dominated habitats consisted of $>60 \%$ shrub cover and $<40 \%$ grass cover. Each habitat type had five replicates. The altitude of study plots ranged from 40 to $120 \mathrm{~m}$.

\section{Data recording}

During the observation period, the total number of butterfly species in each plot was recorded. We recognise that the number of butterflies observed could describe both butterfly density and butterfly activity, but we simplify further discussion by using the term "abundance". The activity (flying, resting or nectaring) of each endemic butterfly species was also noted. When it was not possible to identify them in flight, a specimen was captured using a sweep net and identified in the field using Makris (2003) and Tolman (2001). In addition to this, the plant species on which endemic butterflies were found were recorded in order to determine those preferred for resting or nectaring. Plant species were identified using Viney (1994). Wind speed (Beaufort scale) and the weather conditions were also recorded on each survey day.

\section{Data analysis}

We analyzed the relationships between butterfly abundance, species richness and habitat type using generalised linear mixed modelling and model simplification using R 2.5.1 software. We analysed abundance of all recorded butterfly species and all endemic species (Maniola cypricola, Hipparchia cypriensis and Glaucopsyche paphos), relating abundance, diversity and spe- 
TABLE 1. Selected plots with latitude / longitude coordinates, habitat type and common plant species information. Numbers represent approximate proportion of cover of each plant community.

\begin{tabular}{cccccc}
\hline Plot No. & Latitude & Longitude & Habitat & Shrubs (T, C, S, G, P) & Grasses \\
\hline 1 & 35.3530 & 33.0677 & Shrubland & 0.60 & 0.40 \\
2 & 35.3593 & 33.0417 & Grassland & 0.40 & 0.60 \\
3 & 35.3635 & 33.0229 & Grassland & 0.40 & 0.60 \\
4 & 35.3640 & 33.0228 & Grassland & 0.40 & 0.60 \\
5 & 35.3712 & 32.9811 & Grassland & 0.40 & 0.60 \\
6 & 35.3754 & 32.9758 & Shrubland & 0.75 & 0.25 \\
7 & 35.3533 & 33.0664 & Shrubland & 0.70 & 0.30 \\
8 & 35.3531 & 33.0632 & Grassland & 0.20 & 0.80 \\
9 & 35.3535 & 33.0609 & Shrubland & 0.90 & 0.10 \\
10 & 35.3535 & 33.0596 & Shrubland & 0.90 & 0.10 \\
\hline
\end{tabular}

T-Thymus capitatus; $\mathrm{C}$ - Cistus spp.; $\mathrm{S}$ - Sarcopterium spinosum; $\mathrm{G}$ - Genista sphaceleata $\mathrm{P}$ - Pistacia $\mathrm{spp}$.

cies richness to habitat type, week, wind speed and weather conditions. Repeated visits to the same plots throughout the season resulted in repeated measures of butterfly abundance and species richness. We accounted for this by including plot as a random effect in our models. Recognising that butterfly abundance and richness increased and then decreased as the season progressed, we fitted week as both a linear and a quadratic fixed effect. We modelled counts of butterfly individuals or species using a Poisson error structure, which was never overdispersed. To test the significance of habitat type we removed the interactions between habitat and the quadratic effect of week number, and between habitat and the linear effect of week number, from maximum likelihood versions of the mixed effects models (according to Crawley, 2007), and compared models with and without these interactions using likelihood ratio tests. Similar model simplification tests were also used to assess the significance of wind speed and weather conditions on each response variable.

Finally, we used Simpson's Diversity Index (1-D), applied to the whole-season counts of each butterfly species in each plot, to quantify the butterfly diversity found in each different habitat type using generalised linear modelling with a Gaussian error structure.

TABLE 2. Butterfly species and their total abundance observed in two habitat types.

\begin{tabular}{lcc}
\hline Species name & Grassland & Shrubland \\
\hline Anthocharis cardamines & 46 & 19 \\
Artogeia rapae & 78 & 60 \\
Pieris brassicae & 115 & 71 \\
Colias crocea & 59 & 39 \\
Zerynthia cerisyi & 10 & 5 \\
Euchloea ausonia & 0 & 1 \\
Gonepteryx cleopatra & 12 & 19 \\
Vanessa cardui & 3 & 6 \\
* Glaucopsyche paphos & 4 & 4 \\
* Maniola cypricola & 107 & 67 \\
Pontia edusa & 11 & 6 \\
Chazara briseis & 10 & 6 \\
*Hipparchia cypriensis & 39 & 2 \\
Thymelicus acteon & 7 & 2 \\
Papilio machaon & 0 & 1 \\
Lasiommata maera & 1 & 0 \\
\hline Total abundance & 502 & 308 \\
\hline Total species & 14 & 15 \\
\hline * endemic species & &
\end{tabular}

\section{RESULTS}

\section{Butterfly abundance during the surveys in different habitat types}

During the surveys, a total of 810 individual butterflies from 16 species were recorded across the ten different plots in the Kayalar village region of Cyprus. A total of 502 individuals $(61.9 \%)$ and 14 different species were recorded in grassland dominated habitats and 308 $(38.1 \%)$ individuals and 15 different species were recorded in shrubland dominated habitats. During this study Pieris brassicae (186), Maniola cypricola (174) and Artogeia rapae (138) were the three most abundant species observed (for a complete list see Table 2).

Weekly data for the spring-summer of 2007 from both habitat types indicate that the highest butterfly abundance occurred between Week 9 and Week 11 which related to the end of April - beginning of May (Fig. 2) This was

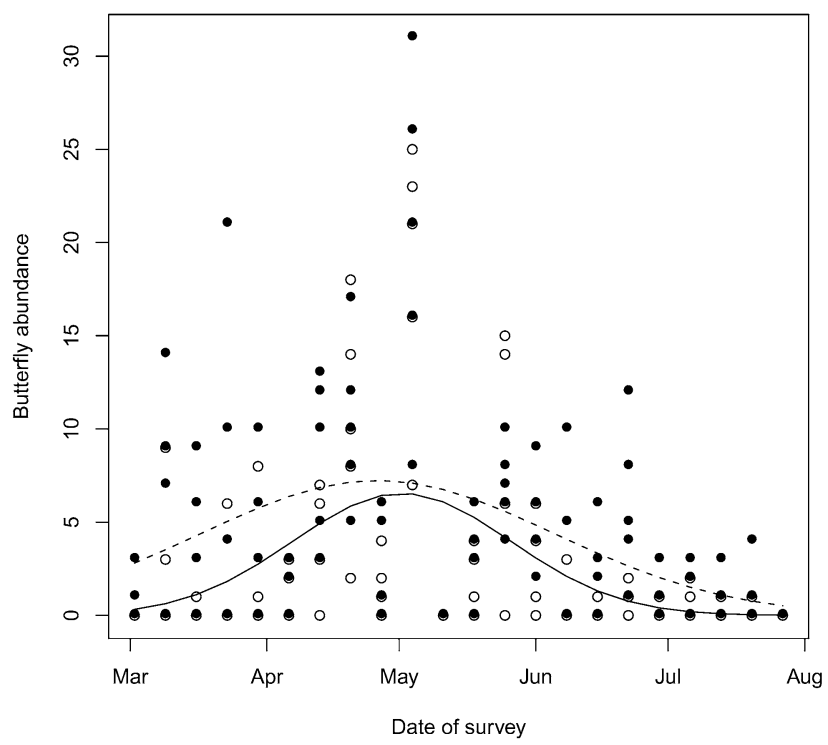

Fig. 2. The abundance of all butterflies observed in two different habitats $(\bullet$ shows the number of individuals seen in each plot in grassland patches, $\bigcirc$ shows the number of individuals seen in each plot in shrubland patches. The fitted relationship between number of individuals and week is signified by dashes for grassland and solid line for shrubland). 


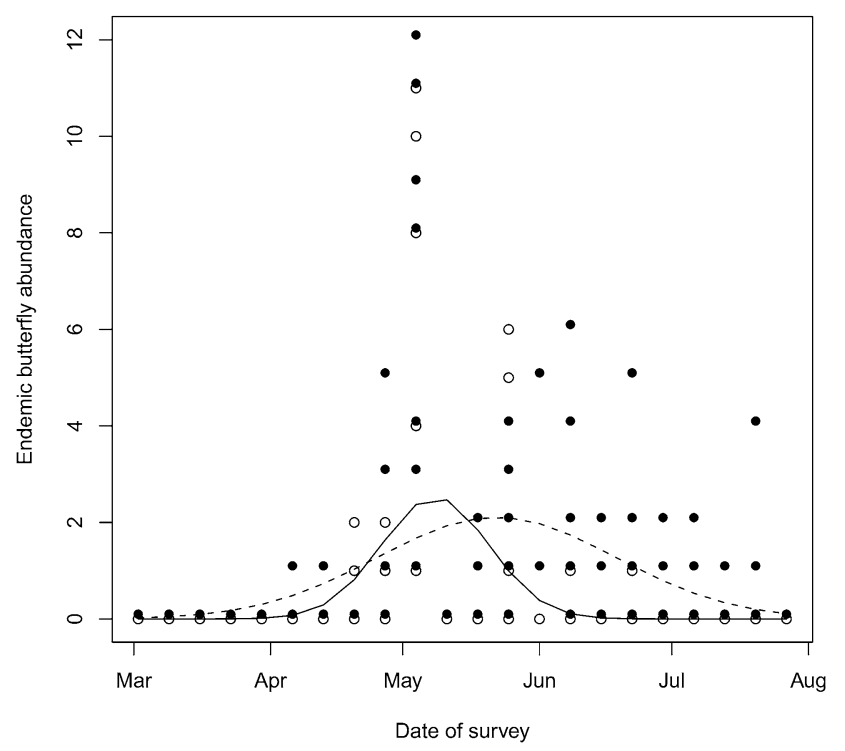

Fig. 3. The abundance of endemic butterflies observed in two different habitat types $(\bullet$ shows the number of endemics seen in each plot in grassland patches, $\bigcirc$ shows the number of endemics seen in each plot in shrubland patches. The fitted relationship between number of endemics and week is signified by dashes for grassland and solid line for shrubland).

expected, as the main flowering period occurs during that time of the year in Cyprus.

\section{Abundance of all butterflies}

We found a significant effect of the habitat type on butterfly abundance, described as an interaction between habitat and the quadratic and linear effect of survey week. In general, there were more individuals present in grassland mosaics than in shrubland mosaics and this statistical interaction demonstrates a longer butterfly season in grassland dominated habitats (Fig. 2 and Table 3). Abundance of all butterflies was not influenced by wind speed. There was however a very significant effect regarding the presence of sun, with more individuals recorded on sunny days as opposed to cloudy days (Table 3 ).

\section{Abundance of all endemic butterflies}

Habitat type had a significant effect on the number of endemic butterflies, due to an interaction between habitat and both quadratic and linear effect of the week (Table

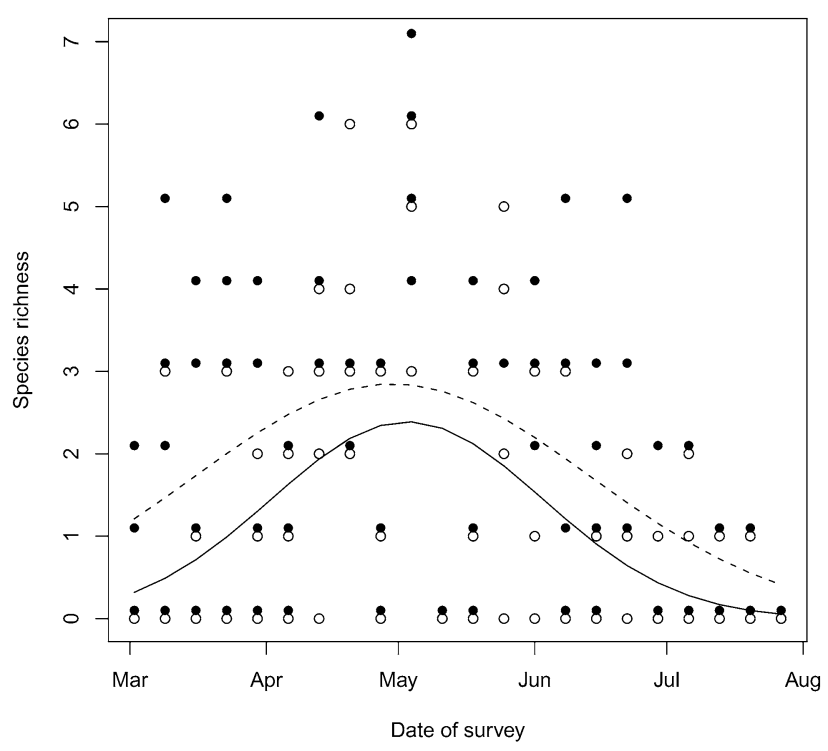

Fig. 4. Species richness in grassland and shrubland habitats ( shows the number of butterfly species seen in each plot in grassland patches, $\bigcirc$ shows the number of species seen in each plot in shrubland patches. The fitted relationship between species richness and week is signified by dashes for grassland and solid line for shrubland).

3). The abundance of endemics was generally higher in grassland dominated habitats, with a more prolonged season in the grasslands (Fig. 3). The abundance of endemic butterflies was also influenced by wind speed (Table 3), with fewer endemics observed on windier days. We tested the weather condition (sunny, partly cloudy or cloudy) effect on butterfly abundance and found that more endemic butterflies were seen on sunny days (Table $3)$.

\section{Species richness of the butterflies}

There was a significant effect of the habitat type on butterfly species richness, due to interactions between habitat type and the quadratic effect of week, and also between habitat and the linear effect of week (Table 3). The number of butterfly species observed was higher in grassland mosaics than in shrubland mosaics. Also, the species richness was higher in grasslands at the beginning and end of the season, compared to shrublands (Fig. 4). There

TABLE 3. Significance tests of fixed effects of date, habitat type and weather conditions on the species richness and abundance of butterflies. Chi-square values are the results of likelihood ratio tests during simplification of maximum likelihood versions of generalised linear mixed models (see statistical methods for details).

\begin{tabular}{lccccc}
\hline \multirow{2}{*}{ Explanatory variable } & \multicolumn{5}{c}{ Response variable } \\
\cline { 2 - 6 } & Richness & Abundance & Endemics & Maniola abundance & Hipparchia abundance \\
\hline \multirow{2}{*}{ Habitat : Week $^{2}$} & $\chi_{1}=9.585$ & $\chi_{1}=51.453$ & $\chi_{1}=33.771$ & $\chi_{1}=7.089$ & $\chi_{1}=4.131$ \\
& $\mathrm{p}=0.002$ & $\mathrm{p}<0.001$ & $\mathrm{p}<0.001$ & $\mathrm{p}=0.008$ & $\mathrm{p}=0.042$ \\
\hline \multirow{2}{*}{ Habitat : Week } & $\chi_{1}=8.856$ & $\chi_{1}=50.457$ & $\chi_{1}=27.639$ & $\chi_{1}=6.162$ & $\chi_{1}=0.021$ \\
& $\mathrm{p}=0.003$ & $\mathrm{p}<0.001$ & $\mathrm{p}<0.001$ & $\mathrm{p}=0.013$ & $\mathrm{p}=0.885$ \\
\hline \multirow{2}{*}{ Sun } & $\chi_{2}=61.344$ & $\chi_{2}=256.240$ & $\chi_{2}=19.040$ & $\chi_{2}=19.569$ & $\chi_{2}=3.073$ \\
& $\mathrm{p}<0.001$ & $\mathrm{p}<0.001$ & $\mathrm{p} \leq 0.001$ & $\mathrm{p} \leq 0.001$ & $\mathrm{p}=0.215$ \\
\hline \multirow{2}{*}{ Wind } & $\chi_{1}=0.278$ & $\chi_{1}=3.258$ & $\chi_{1}=10.990$ & $\chi_{1}=16.896$ & $\chi_{1}=0.917$ \\
& $\mathrm{p}=0.598$ & $\mathrm{p}=0.007$ & $\mathrm{p} \leq 0.001$ & $\mathrm{p} \leq 0.001$ & $\mathrm{p}=0.338$ \\
\hline
\end{tabular}




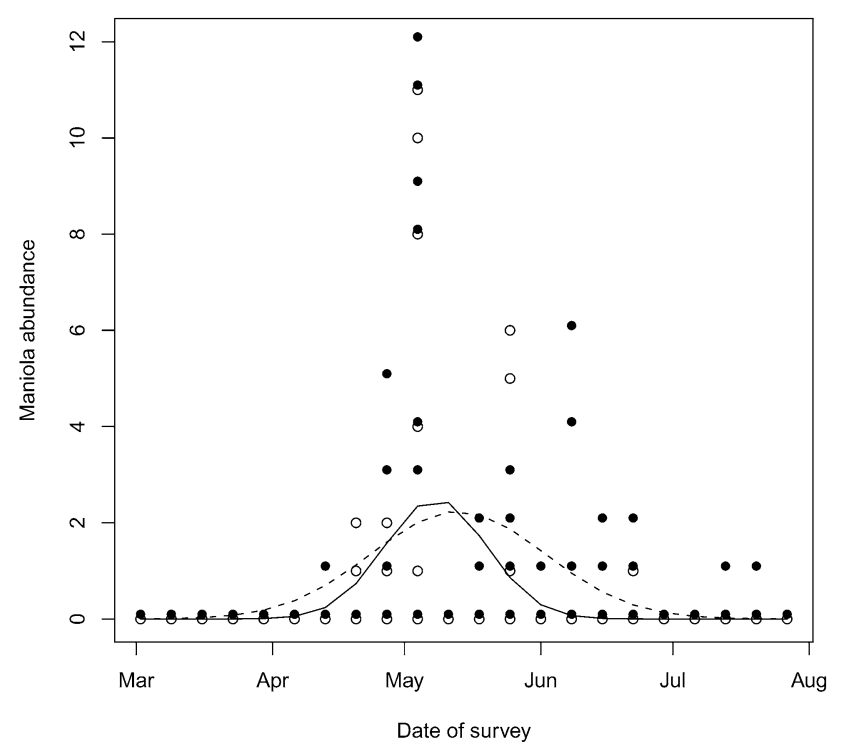

Fig. 5. The abundance of Maniola cypricola observed in two different habitat types ( $\bullet$ shows the number of M. cypricola seen in each plot in grassland patches, $\bigcirc$ shows the number of M. cypricola seen in each plot in shrubland patches. The fitted relationship between number of M. cypricola and week is signified by dashes for grassland and solid line for shrubland).

was no detectable effect of wind on species richness, although species richness was higher on sunny days in both types of habitat within the garrigue ecosystem (Table 3).

\section{Abundance of Maniola cypricola}

We used the same analysis framework for M. cypricola as we used in our previous analysis. There was a significant effect of the habitat type on the abundance of $M$. cypricola (Fig. 5 and Table 3). We also observed fewer M. cypricola on windy days, but more on sunny days (Table 3).

\section{Abundance of Hipparchia cypriensis}

The same model framework was used to analyse the abundance of $H$. cypriensis in different habitat types. There was a significant effect of the habitat type on the abundance of $H$. cypriensis due to the interaction between habitat type and the quadratic effect of week. However in

TABLE 4. Resting behaviour of endemic butterfly species. Numbers represent total observations across all plots of each habitat type for the whole season.

\begin{tabular}{lccccc}
\hline \multirow{2}{*}{ Plant species } & \multicolumn{4}{c}{ Resting site } \\
\cline { 2 - 3 } & \multicolumn{3}{c}{ Maniola } & & \multicolumn{2}{c}{ Hipparchia } \\
\cline { 2 - 3 } \cline { 5 - 6 } Cistus spp. & 2 & 0 & & 0 & 0 \\
Poa spp. & 20 & 3 & & 0 & 0 \\
Olea europea & 1 & 0 & & 36 & 0 \\
Pistacia lentiscus & 19 & 1 & & 1 & 0 \\
Teucrium & 0 & 1 & & 0 & 0 \\
micropoidoides & 0 & 1 & & 0 & 0 \\
Thymus capitatus & 0 & 0 & & 0 & 1 \\
Rock & 0 & 0 &
\end{tabular}

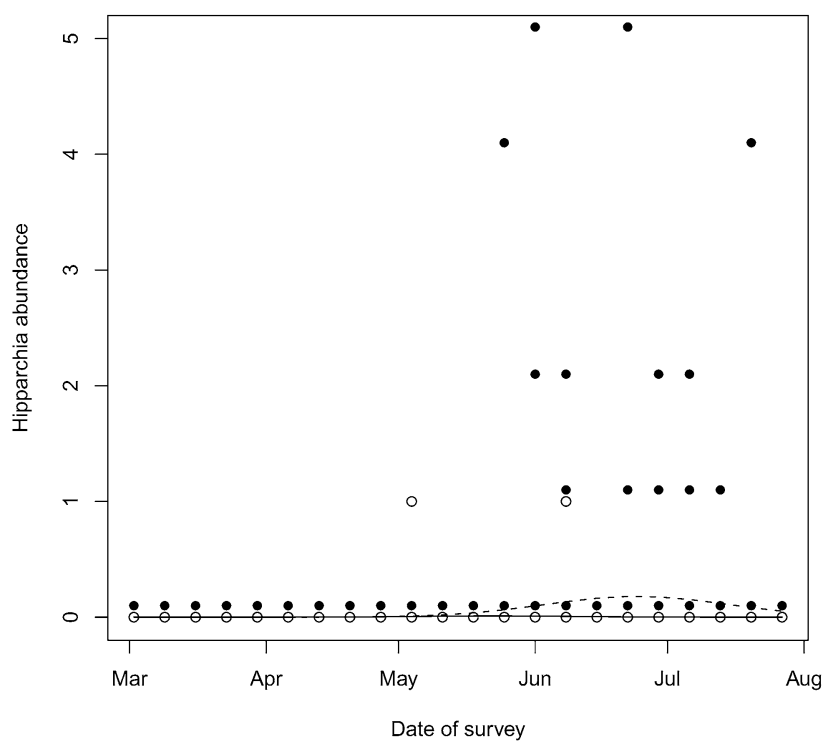

Fig. 6. The abundance of Hipparchia cypriensis observed in two different habitat types ( $\bullet$ shows the number of $H$. cypriensis seen in each plot in grassland patches, $\bigcirc$ shows the number of $H$. cypriensis seen in each plot in shrubland patches. The fitted relationship between number of $H$. cypriensis and week is signified by dashes for grassland and solid line for shrubland).

this case the interaction between habitat type and the linear effect of week was not significant (Fig. 6 and Table 4). We found no significant effect of wind or sun on the abundance of $H$. cypriensis.

\section{Simpson's Index of Diversity}

We analysed Simpson's Index of Diversity in grassland and shrubland habitats using a General Linear Model (GLM). Diversity was not significantly different in the two different habitat types $\left(\mathrm{F}_{1,8}=0.0515, \mathrm{p}=0.8261\right)$.

\section{Records on behaviour of endemic butterflies}

During the surveys, 107 M. cypricola were recorded in grassland habitat plots and 67 in shrubland. This result was expected as its larval host plants are meadow grasses (Poaceae Family, Makris, 2003). M. cypricola specimens were recorded nectaring on Eryngium creticum, Cistus spp. and Teucrium micropoidoides flowers. Teucrium micropoidoides is an aromatic plant and endemic to Cyprus (Viney, 1994). Also, M. cypricola was observed mainly resting on Pistacia lentiscus, Thymus capitatus

TABLE 5. Nectaring behaviour of the two endemic butterflies. Numbers represent total observations across all plots of each habitat type for the whole season.

\begin{tabular}{lccccc}
\hline & \multicolumn{5}{c}{ Nectaring } \\
\cline { 2 - 3 } \cline { 5 - 6 } Plant species & \multicolumn{3}{c}{ Maniola } & & \multicolumn{2}{c}{ Hipparchia } \\
\cline { 2 - 3 } \cline { 5 - 6 } $\begin{array}{l}\text { Cistus spp. } \\
\text { Eryngium }\end{array}$ & 0 & & & Grassland & Shrubland \\
$\begin{array}{l}\text { creticum } \\
\begin{array}{l}\text { Teucrium } \\
\text { micropoidoides }\end{array}\end{array}$ & 1 & 0 & & 0 & 0 \\
\hline
\end{tabular}


and various grass spp. (Table 4 and 5). The other Cypriot Satyrid species, $H$. cypriensis was also recorded in higher numbers in grassland dominated habitats (39) than shrubland dominated habitats (2): its larval host plants are also meadow grasses (John \& Parker, 2002; Makris, 2003, Table 4). During these observations H. cypriensis was only found resting on olive tree trunks. The other endemic species of Cyprus, Glaucopsyche paphos (Lycaenidae), was recorded in similar numbers from both habitat types and was only recorded in flight.

\section{DISCUSSION}

We studied the seasonal dynamics of butterfly abundance and species richness in grassland and shrubland mosaic patches within the garrigue ecosystem of the north-western part of Cyprus. We found that the diversity of butterflies was similar between these two habitats when measured across the whole season. However, grassland dominated garrigue patches harboured consistently more species than shrubland patches. This was not surprising, as all Satyridae family butterflies in Cyprus rely on Poaceae family grasses as a food plant (Makris, 2003). Furthermore, the abundance of butterflies was higher in grassland patches than in shrubland patches during early and late phases of the main butterfly flight season. This may be due to higher air temperatures in grassland in the early season, or the use of open areas to search for mates. In the late, hot season, butterflies may be resting in the shade of shrubs in shrubland patches, making them less conspicuous.

The abundance of endemic butterflies was also significantly higher in grassland dominated mosaics, with a longer season than in shrubland dominated mosaics. Particularly $M$. cypricola was more abundant in grasslands than in shrublands during the late phase of the season. The larval host plants of Cypriot endemics (Maniola cypricola and Hipparchia cypriensis) consist of various plant species from the Poaceae family. Adults of both these endemic species prefer to feed on Rockrose (Cistus creticus) flowers (John \& Parker, 2002; Makris, 2003). The larval host plants of the other endemic butterfly species of Cyprus (Glaucopsyche paphos) are Genista sphaceleta and Calycotome villosa bushes (Makris, 2003). Maniola cypricola and Hipparchia cypriensis were both recorded in higher numbers in grassland patches when compared with shrubland patches. The peak number of M. cypricola was similar in both habitat types: this is possibly due to the emergence of adults at the end of April, which coincides with the flowering of Cistus ssp. Also, most of the M. cypricola butterflies in grassland habitats were recorded while they were resting on the shrub Pistacia lentiscus. It appears that the endemic butterflies of Cyprus prefer to use heterogeneous grassland and shrubland habitats, which has also been shown in Sardinian endemics (Grill et al., 2005). If we look at non-endemic species in Cyprus, many of the Lycaenidae, Pieridae and Satyridae species prefer shrubland habitats especially when resting and nectaring (Makris, 2003; Özden et al., 2008).
Many butterfly species are negatively affected by changes in mountain grassland management in the Mediterranean region (Grill et al., 2002). The major threats to these grassland habitats are agricultural intensification, overgrazing, fire and building development (Grill et al., 2002; Stefenascu et al., 2004). Currently, the major threat to garrigue habitats in Cyprus is the uncontrolled building development which is occurring along the northern coast of the island.

Our results suggest not only that the garrigue ecosystem is an important habitat for endemic butterfly species, but also that it is very important to conserve mosaics of shrubland and grassland habitats for all Cypriot butterfly species. Grassland patches have a very high ecological value, as they consist of many larval host plants for the Cypriot butterflies and also they may be important for them for other functions, such as adult feeding (nectaring) resources and/or mating locations. Shrubland patches, on the other hand, contain key plant species for nectaring, resting and shelter.

In conclusion, the results presented in this paper provide valuable information on Cypriot butterflies and their close relationship with the grassland-shrubland mosaics in garrigue ecosystem. This information should be used by local authorities when implementing management plans of the EU Habitats Directive within this northwestern Special Protected Area. It is well known that host plants are important for butterfly conservation. However, it is equally important to know their preferred nectaring, roosting, resting, mating plant species or appropriate physical structures (such as rocks and bare ground) (Shreeve et al., 2004; Tudor et al., 2004). Further research is needed in order to discover which plant species and habitats are the preferred sources of nectar for butterflies in this type of ecosystem, particularly for endemics over a longer time frame.

Our results provide not only valuable knowledge about the important habitats for Cypriot butterflies, but additionally highlight the need for their conservation in the face of large scale building developments along this coastal region.

ACKNOWLEDGEMENTS. This research was supported by the European Social Fund. The authors thank W. Fuller, A. Broderick, R. Wilson and O. Lewis for their useful comments on drafts of this manuscript.

\section{REFERENCES}

Beccaloni G.W. \& Gaston K.J. 1995: Predicting the species richness of Neotropical forest butterflies: Ithominae (Lepidoptera: Nymphalidae) as indicators. Biol. Conserv. 71: 77-86.

Blondel J. \& Aronson J. 2004: Biology and Wildlife of the Mediterranean Region. Oxford University Press, Oxford, 328 pp.

Crawley M.J. 2007: The R Book. John Wiley \& Sons, Chichester, $942 \mathrm{pp}$.

DAPPORTo L. \& DenNIS R.L.H. 2008: Island size is not the only consideration. Ranking priorities for the conservation of butterflies on Italian offshore islands. J. Insect Conserv. 12: 237-249. 
Dennis R.L.H., Dapporto L., Shreeve T.G., John E., Coutsis J.G., Kudrna O., SaArinen K. \& Ryrholm N. 2008: Butterflies of European islands: the implications of the geography and ecology of rarity and endemicity for conservation. $J$. Insect Conserv. 12: 205-236.

Dover J., Sparks T., Clarke S., Gobbett K. \& Glossop S. 2000: Linear features and butterflies: the importance of green lanes. Agric. Ecosyst. Environ. 80: 227-242.

Davies C.E., Moss D. \& Hill M. (eds) 2004: EUNIS Habitat Classification. Report to European Environment Agency, Copenhagen \& European Topic Centre on Nature Protection and Biodiversity, Paris, $302 \mathrm{pp}$.

Grill A., Crnjar R., Casula P. \& Menken S. 2002: Applying the IUCN threat categories to island endemics: Sardinian butterflies (Italy). J. Nature Conserv. 10: 51-60.

Grill A., Knoflach B., Cleary D.F.R. \& Kati V. 2005: Butterfly, spider, and plant communities in different land-use types in Sardinia, Italy. Biodiv. Conserv. 14: 1281-1300.

Ornat L.A. \& Correas E. 2003: Management of Protected Areas in the Mediterrenean. Assessment and Opportunities of Networks and Action Plans. IUCN Centre for Mediterranean Cooperation, Malaga, $149 \mathrm{pp}$.

John E. \& PARKer R. 2002: Dispersal of Hipparchia cypriensis (Holik, 1949) (Lepidoptera: Nymphalidae, Satyridae) in Cyprus, with notes on its ecology and life history. Entomol. Gaz. 53: 3-18.

John E., Coutsis J.G. \& Makris C. 2006: A review of records for Colias erate [Esper, (1805)] (Lepidoptera: Pieridae) in Cyprus: Were they all yellow forms of Colias croceus (Geoffroy, 1785)? Entomol. Gaz. 57: 3-12.

Lewis O.T., Wilson R.J. \& Harper M.C. 1998: Endemic butterflies on Grande Comore: habitat preferences and conservation priorities. Biol. Conserv. 85: 113-121.

MAKris C. 2003: Butterflies of Cyprus. Bank of Cyprus Cultural Foundation, Nicosia, $327 \mathrm{pp}$.

Medail F. \& Quezel P. 1999: Biodiversity hotspots in the Mediterranean Basin: Setting conservation priorities. Conserv. Biol. 13: 1510-1513.

Myers N. 1990: The biodiversity challenge: expanded hotspots analysis. Environmentalists 10: 243-256.

Myers N., Mittermeier R.A., Mittermeier C.G., Fonseca, G.A.B. \& Kent J. 2000: Biodiversity hotspots for conservation priorities. Nature 43: 853-858.

NADIN P. 2008: The Mediterranean region: a showcase of biodiversity. Statistics in Focus, Environment and Energy 12/2008: 8 pp.

Olivier A. 1993: The Butterflies of the Greek Island of Ródos: Taxonomy, Faunistics, Ecology and Phenology with a Tenta- tive Synthesis on the Biogeography of the Butterflies of Kriti (Crete), Kárpathos, Ródos, the Eastern Aegean Islands and Kipros (Cyprus) (Lepidoptera: Hesperioidea \& Papilionoidea). Vlaamse Vereniging voor Entomologie, Antwerpen, $250 \mathrm{pp}$.

Özden Ö., Ciesla W.M., Fuller W.J. \& Hodgson D.J. 2008: Butterfly diversity in Mediterranean islands and in Pentadaktylos Pinus brutia forests of Cyprus. Biodiv. Conserv. J. 17: 2821-2832.

Phillips A. \& Bracewell F. 2001: Protected Areas a Challenge for North Cyprus. Report and Recommendations Following a Visit to North Cyprus. Middle East Environmental Ltd., Nicosia (TCC), Cyprus, 49 pp.

Shreeve T.G., Dennis L.H.R. \& Dyck H.V. 2004: Resources, habitats and metapopulations - whither reality? Oikos 106: 404-408.

Stefanescu C., Penuelas J. \& Filella I. 2005: Butterflies highlight the conservation value of hay meadows highly threatened by land-use changes in a protected Mediterranean area. Biol. Conserv. 126: 234-246.

Tolman T.W. 2001: Photographic Guide to the Butterflies of Britain and Europe. Oxford University Press, Oxford, 305 pp.

Tsintides T.C., Hadjikyriakou G.N. \& Christodolou C.S. 2002: Trees and Shrubs in Cyprus. Anastasios G Leventis Foundation and Cyprus Forest Association, Lefkosia, 442 pp.

Tudor O., Dennis R.L.H., Greatorex-Davies J.N. \& Sparks T.H. 2004: Flower preferences of woodland butterflies in the UK: nectaring specialists are species of conservation concern. Biol. Conserv. 119: 397-403.

UlRich W. \& BuszKo J. 2003: Species - area relationships of butterflies in Europe and species richness forecasting. Ecography 26: 365-373.

USAID 2006: FAA 119 Biodiversity Analysis, United States Agency for International Development, $81 \mathrm{pp}$.

van SwaAy C. \& Warren M. 1999: Red Data Book of European Butterflies (Rhopalocera). Nature and Environment, No. 99. Council of Europe Publishing, Strasbourg.

van Swaay C. \& Warren M. 2006: Prime butterfly areas of Europe: an initial selection of priority sites for conservation. $J$. Insect Conserv. 10: 5-11.

VineY D.E. 1994: An Illustrated Flora of North Cyprus. Koeltz Scientific Books, Koenigstein, 697 pp.

Zamora J., Verdu J.R. \& Galante E. 2007: Species richness in Mediterranean agroecosystems: Spatial and temporal analysis for biodiversity conservation. Biol. Conserv. 134: 113-121.

Received August 6, 2010; revised and accepted December 20, 2010 